\title{
Effect of polysaccharide from Bacillus subtilis sp. on cardiovascular diseases and atherogenic indices in diabetic rats
}

\author{
Mona A. M. Ghoneim ${ }^{1}$, Amal I. Hassan ${ }^{1 *}$, Manal G. Mahmoud ${ }^{2}$ and Mohsen S. Asker ${ }^{2}$
}

\begin{abstract}
Background: Diabetes mellitus induces chronic complications such as cardiovascular damage, cataracts and retinopathy, nephropathy, and polyneuropathy. The main aim of the study was to isolate and identify both of bacterial strain and exopolysaccharide to assess the possible efficiency of exopolysaccharide (BSEPS) from Bacillus subtilus sp .suppress on cardiovascular diseases, atherogenic and coronary risk indices in diabetic rats.

Methods: The bacterial strain used was isolated from mangrove tree sediment by serial dilution and the spreadplate technique and identified by morphological, physiological, and biochemical characteristics, and by 16S rRNA analysis. The BSEPS was extracted from the bacterial supernatant by four volumes child ethanol then the functional groups, MW and chemical analysis were detected by Fourier-transform infrared (FTIR), gel permeation chromatograph (GPC) and High-performance liquid chromatography (HPLC). Also an antioxidant activity was measured by using 2,2-diphenyl-1-picrylhydrazyl (DPPH). Thirty-two male Sprague-Dawley rats were equally randomized into four groups: control group supplemented with normal saline (Group I); the second group supplemented with BSEPS (Group II); diabetic group supplemented with normal saline (Group III) and the diabetic group supplemented with BSEPS (Group IV). Diabetes was induced by Streptozotocin (STZ) (65 mg/kg BW) intraperitoneally. BSEPS (100 mg/kg BW) was administered orally for four weeks, following STZ induction.

Results: The isolated strain was identified based on 165 rRNA sequence as Bacillus subtilis sp. suppress. A preliminary chemical analysis of BSEPS indicated that the monosaccharides were mannuronic acid, glucuronic acid, glucose, galactose, and mannose in a molar ratio of 1.6:1.5:1.0:2.3:1.4, respectively, with a molecular weight of $1.66 \times$ $10^{4} \mathrm{~g} \mathrm{~mol}^{-1}$ and a molecular number of $7.64 \times 10^{3} \mathrm{~g} \mathrm{~mol}^{-1}$. BSEPS inhibited 2,2-diphenyl-1-picrylhydrazyl radical activity, and BSEPS supplement reduced glucose $(p<0.05)$ and troponin levels while insulin levels increased $(p<$ 0.05). BSEPS also reduced total serum cholesterol, low-density lipoprotein (LDL), very low-density lipoprotein (VLDL), and triglycerides, and elevated high-density lipoprotein-cholesterol (HDL). In parallel, intercellular adhesion molecule (ICAM), and vascular cell adhesion molecule (VCAM) levels in STZ-induced diabetic rats were reduced. Moreover, polysaccharides reduced atherogenic and coronary risk indices, which were confirmed by histopathological examination of the heart and aorta.
\end{abstract}

Conclusions: Our study suggests that BSEPS improves hyperglycemia, dyslipidemia, and cardiovascular disease risk in STZ-induced diabetic rats.

Keywords: Streptozotocin, Bacillus subtilis, Exopolysaccharide, Diabetic, Lipid profile, Cardiovascular disease

\footnotetext{
* Correspondence: aml_h@hotmail.com

'Department of Radioisotopes, Nuclear Research Centre, Atomic Energy

Authority, Dokki, Giza, Egypt

Full list of author information is available at the end of the article
} 


\section{Background}

Diabetes mellitus is a heterogeneous combination of chronic perturbations of carbohydrate, lipid, and protein metabolism characterized by increased blood glucose owing to partial or absolute insulin deficiency [1]. The World Health Organization estimates that diabetes affects 285 million people globally, and current predictions estimate that 438 million people will be diabetic by 2030 $[2,3]$. Pharmacological treatment of diabetes relies on oral hypoglycemic agents and insulin, but these approaches currently used in clinical practice either do not restore normal glycemic levels in most patients or their levels change over time. Moreover, continuous use of synthetic anti-diabetic drugs causes side effects and toxicity [4]. Because of the limitations and unmet goals associated with anti-diabetic drugs, an increased number of diabetic patients globally currently resort to complementary and alternative medicine [5]. Therefore, natural and non-toxic anti-diabetic drugs are inevitable for diabetic therapeutics such as exopolysaccharides (EPSs) [6]. Metabolic abnormalities and oxidizing stress arise at early stages of diabetes and are significant risk factors for complications of the nervous, cardiovascular, excretory, and reproductive systems [7]. Several remedial agents are effective for hyper-cholesterolemic patients and are used successfully for treatment. A variety of studies have demonstrated that the mechanism of lipidlowering drugs can reduce the number of cardiovascular events and mortality from coronary disease [8]. EPSs are natural macromolecules present throughout the growth of many microorganisms. An inordinate number of bacterial EPSs has attracted the interest of many scientists who have examined their composition, structure, biosynthesis, and functional properties [9]. A number of reports have been published on the anti-atherosclerosis effect of acidic EPSs and the inhibition of total cholesterol [10]. Atherosclerosis is combined with a broad spectrum of cardio-metabolic disturbances, including diabetes, arteriosclerosis, and cardiovascular disease. $\mathrm{Ba}$ cillus sp. is one of the marine bacteria that produce complex homo-and/or heteropolysaccharides. Bacillus sp. produce a variety of EPSs such as levan [11] and $\beta$ (1-3)-glucan [12], and hetero-polymers composed mainly of neutral sugar [13], uronic acid [14], uncommon sugar [15], or sugar protein conjugates [16]. The form and mechanisms of the pharmaceutical effects of medical specialty EPSs on diseases have been largely elucidated, and normal EPSs with different curative potential have been studied and even included in therapies. Thus, the present study was designed to evaluate the potential beneficial effect of the exopolysaccharides (BSEPS) from Bacillus subtilus sp. suppress from marine on serum lipid parameters and cardiovascular disease risk predictor in normal and Streptozotocin-induced diabetic rats. Additionally, the chemical structure of purified BSEPS was elucidated after identification of isolated bacterial strain.

\section{Methods \\ I- In vitro study \\ Screening and identification}

Marine sediment collected from the mangrove tree (ElEin El-Sokhna, Egypt) was suspended in $90 \mathrm{~mL}$ sterile water. Serial dilution and the spread-plate technique were used for growing different bacteria. The screening medium contained (all reagents in $\mathrm{g} / \mathrm{L}$ ) glucose 20; yeast extract $0.1 ; \mathrm{CaCO}_{3} \quad 1 ; \mathrm{NH}_{4} \mathrm{NO}_{3} \quad 0.8 ; \mathrm{K}_{2} \mathrm{HPO}_{4} \quad 0.6$; $\mathrm{KH}_{2} \mathrm{PO}_{4} 0.5 ; \mathrm{MgSO}_{4} .7 \mathrm{H}_{2} \mathrm{O} 0.05$, and $\mathrm{MnSO}_{4} .4 \mathrm{H}_{2} \mathrm{O} 0.1$ in $75 \%$ sea water [17]. The initial screening selected for smooth, ropy, and mucous colonies from each plate, with subcultures maintained on marine nutrient agar medium until a pure isolate was obtained. Pure colonies were then inoculated into $50 \mathrm{~mL}$ of marine nutrient medium in a $250-\mathrm{mL}$ conical flask, and incubated at $37^{\circ} \mathrm{C}$ in a rotary shaker at $120 \mathrm{rpm}$ for $48 \mathrm{~h}$. After centrifugation, supernatant was mixed with four volumes of chilled ethanol. The precipitate was collected by centrifugation and the pellets washed by acetone and diethyl ether, and dried at $50{ }^{\circ} \mathrm{C}$ until constant weight. EPS production was determined by the phenol-sulfuric acid method [18]. Strain NRC-108, which produces elevated EPS levels, was identified on the basis of morphological, physiological, and biochemical characteristics [19] combined with $16 \mathrm{~S}$ rRNA sequence analysis. The universal primers delineated by Weisburg et al. [20], particularly ITS1 and ITS4, were used to amplify the $16 \mathrm{~S}$ rRNA gene sequence. A single, discrete, polymerase chain reaction amplicon was resolved on agarose. Sequencing products were resolved on an Applied Biosystems (Foster City, CA, USA) model 3730 XL, automated DNA sequencing system. Data were submitted to GenBank and the sequence compared with the GenBank database (http://www.ncbi.nlm.nih.gov) using BLAST [21].

\section{Isolation and purification of EPSs}

Inoculums was prepared by transferring one loop full of culture (NRC-108) from marine nutrient slant to an Erlenmeyer flask $(250 \mathrm{~mL})$ consisted of $50 \mathrm{ml}$ seed medium, (g/L) sucrose 20; yeast extract 2; peptone and $75 \%$ sea water [22]. The seed cultures were grown at $37{ }^{\circ} \mathrm{C}$ on a rotary shaker incubator at $150 \mathrm{rpm}$ for $24 \mathrm{~h}$. After incubation, $3 \mathrm{ml}$ of the seed culture was transferred into an Erlenmeyer flask (250-mL) containing $50 \mathrm{ml}$ of fermentation medium (g/L) sucrose 50; peptone 4; yeast extract 2 in $75 \%$ sea water $\mathrm{pH} 7.0$ [23]. The fermentation cultures were then incubated at $37{ }^{\circ} \mathrm{C}$ with shaking at $150 \mathrm{rpm}$ for 3 days. The fermented broth was collected and centrifuged at $3500 \mathrm{xg}$ at $4{ }^{\circ} \mathrm{C}$ for $30 \mathrm{~min}$ 
and dialyzed three times $(1000 \mathrm{~mL} \times 3)$ against flowing tap-water using dialysis tubing (MWCO 2000) for $48 \mathrm{~h}$. The dialyzed solution through precipitation with four volumes chilled ethanol, the precipitate washed with acetone, diethyl ether and dried at $40{ }^{\circ} \mathrm{C}$ until constant weight. The crude EPS was re-dissolved in deionizaed water and forced through a filter $(0.45 \mathrm{~mm})$, then applied to a column $(2.5 \times 70 \mathrm{~cm}$, i.d. $)$ of DEAE-cellulose. After loading with a sample, the column was eluted with a gradient $\mathrm{NaCl}$ solution $(0.0-1.0 \mathrm{M})$, and the procedure was monitored by the phenol- $\mathrm{H}_{2} \mathrm{SO}_{4}$ method mentioned above. One polysaccharide active fraction (BSEPS) was collected, dialyzed and lyophilized. BSEPS was used for activity assessment and structural analysis [24].

\section{Chemical analyses}

Purified BSEPS (50 mg) was subjected to hydrolysis with $6 \mathrm{~N} \mathrm{HCl}$ for $4 \mathrm{~h}$ at $100{ }^{\circ} \mathrm{C}$ in a sealed tube. Excess acid was removed by evaporation on a water bath at $40{ }^{\circ} \mathrm{C}$ and co-distilled with water $(1 \mathrm{~mL} \times 3)$ [25]. Uronic acid content was determined by measuring the absorbance at $525 \mathrm{~nm}$ using the m-hydroxybiphenyl colorimetric procedure and with glucuronic acid as the standard [26]. Sulfate was measured using the turbidimetric method [27] with sodium sulfate as the standard. Nacetylglucosamine was estimated by the Morgan and Elson reaction [28]. Ultraviolet-visible (UV-vis) spectroscopy analyses were conducted on a UV-vis spectrophotometer (2401PC; Shimadzu, Kyoto, Japan). BSEPS solution was prepared by suspending the sample in distilled water to $1.0 \mathrm{mg} / \mathrm{mL}$ for UV-vis measurement at 190-700 nm. BSEPS monosaccharide composition was determined by High Performance Liquid Chromatography (HPLC) on a Shimadzu Shim-Pack SCR-101 N column $(7.9 \mathrm{~mm} \times 30 \mathrm{~cm}$, i.d.), using deionized water as the mobile phase (flow rate $0.5 \mathrm{~mL} / \mathrm{min}$ ), as described by El-Sayed et al. [29].

\section{Fourier-transform infrared spectroscopy}

The Fourier-transform infrared spectrum of BSEPS was measured on a Bruker 500-IR Spectrophotometer (Billerica, MA, USA). The sample was mixed with $\mathrm{KBr}$ powder, ground, and pressed into 1-mm pellets for Fourier-transform infrared measurements in the range of $400-4000 \mathrm{~cm}^{-1}$ [30].

\section{Molecular-weight determination}

BSEPS molecular weight was determined on an Agilent 1100 HPLC system equipped with a refractive index detector and FPl gel particle $(5 \mu \mathrm{m})$, three columns of pore type $\left(100,104\right.$, and $\left.105 \mathrm{~A}^{\circ}\right)$ in series, length $7.5 \times$ $300 \mathrm{~mm}(1000,5000000)$ for DMF solvent Styrogel HRDMF, $3 \mu \mathrm{m}(7.8 \times 300 \mathrm{~mm})$ (Waters, Milford, MA, USA). One column $(5000-600,000)$ was used for water solvent (polyethylene oxide/glycol standard) PL aquagel, $\mathrm{OH} 7.5 \mathrm{~mm}$ and $30 \mu \mathrm{m}$ pore, 8 um particle size. Sample $(0.01 \mathrm{~g})$ was dissolved in $2 \mathrm{~mL}$ of solvent and filtrated $(0.45 \mathrm{~mm})$ and transferred to a gel-permeation chromatography (GPC) device [31]. Number average molecular weight $(\mathrm{Mn})$ and number average molecular weight $(\mathrm{Mw})$ were directly calculated according to the definition of $\mathrm{Mn}$ and $\mathrm{Mw}$ using molecular weight and refractive index signal values at each elution volume [32].

\section{BSEPS scavenging activity of DPPH free radicals}

BSEPS free radical scavenging activity was measured against DPPH radicals using the method of Asker et al. [33]. DPPH ethanol solution (5 $\mathrm{mL}$, freshly prepared) was added to $1 \mathrm{~mL}$ of BSEPS solution $(30,50,70$, and $\left.100 \mu \mathrm{g} \mathrm{mL}^{-1}\right)$. Solutions were mixed vigorously and incubated at room temperature in the dark for 30, 60, 90, and $120 \mathrm{~min}$. Supernatant absorbance was measured at $517 \mathrm{~nm}$. A lower absorbance indicates higher free radical scavenging activity, as determined from graphing inhibition percentage plotted against compound concentration. All experiments were carried out in triplicate and averaged. The ability to scavenge DPPH radicals was calculated using the following equation:

$$
\begin{aligned}
\text { Scavenging ability }(\%)=[ & \left(\mathrm{OD}_{517 \text { of control }}-\mathrm{OD}_{517 \text { of sample }}\right) \\
& \left./ \mathrm{OD}_{517 \text { of control }}\right] \times 100
\end{aligned}
$$

\section{II- In vivo study}

\section{Animals}

Thirty-two male Sprague-Dawley rats (180-200 g) were used in this study. Rats were purchased from the laboratory animal colony of the Egyptian Organization for Biological Products and Vaccines (VACSERA) (Helwan, Cairo, Egypt). The animals were housed in the Animal House of the Radioisotopes Department, Atomic Energy Authority, Egypt, under hygienic conditions and fed for 1 week on a basal diet for adaptation and supplied with water ad libitum. The Animal Care Committee of the National Centre for Radiation Research and Technology, Cairo, Egypt, approved the treatment protocol, following the guidelines of the National Institutes of Health.

\section{Induction of diabetes in experimental rats}

Diabetes was induced by a single intraperitoneal injection of a freshly buffered $(0.02 \mathrm{M}$ citrate, $\mathrm{pH}$ 4.5) solution of STZ (Sigma Chemical Co., St. Louis, MO, USA) at a dosage of $65 \mathrm{mg} / \mathrm{kg}$ body weight, as described previously [34]. After $72 \mathrm{~h}$ of STZ administration, tail vein blood was collected to determine fasting blood glucose levels. Rats with fasting blood glucose $\geq 200 \mathrm{mg} / \mathrm{dL}$ were considered diabetic and included in the experiments [35]. Treatment with EPS was after the last STZ 
injection. Blood samples were drawn at the end of the study (30 days).

\section{Acute toxicity $\left(\mathrm{LD}_{50}\right)$ test for BSEPS}

Acute toxicity $\left(\mathrm{LD}_{50}\right)$ was determined for 18 rats in two phases using the method of Lorke [36]. In the initial phase, the rats were divided into three groups of three rats each. They were orally treated with 10,100 , and $1000 \mathrm{mg} / \mathrm{kg}$ of extract and observed for $24 \mathrm{~h}$ for mortality. In the second phase, rats were grouped into three groups of three rats each and orally treated with the extract at varying doses $(1600,2900$, and $5000 \mathrm{mg} / \mathrm{kg})$. Rats were observed for $24 \mathrm{~h}$ and the final $\mathrm{LD}_{50}$ value was determined from the minimum concentration (death) and maximum concentration (survival) of the dose as follows:

$$
\mathrm{LD}_{50}=\left(\mathrm{M}_{0}+\mathrm{M}_{1}\right) / 2,
$$

where $M_{0}$ is the highest dose of test substance with survival and $M_{1}$ is the lowest dose of test substance resulting in death.

\section{Experimental design}

After 1 week of adaptation, rats were divided into four groups of eight rats each as follows: Group I served as a negative control (a single intraperitoneal injection of freshly buffered [0.02 M citrate, $\mathrm{pH} 4.5]$ without STZ) [34]. Rats were injected with normal saline $(0.5 \mathrm{~mL}$, orally) 3 days later and every other day for 30 days. Group II was administered normal BSEPS (100 mg/kg BW) dissolved in saline. Group III was given STZ $(65 \mathrm{mg} / \mathrm{kg}$ BW) dissolved in citrate buffer ( $\mathrm{pH} 4.5)$ and injected intraperitoneally within $10 \mathrm{~min}$ after preparation. Rats were administered with normal saline $(0.5 \mathrm{~mL}$, orally) 3 days later and every other day for 30 days. Group IV consisted of diabetic rats who received daily BSEPS orally, for 30 days. Normal groups were provided common commercial rat chow. Diabetes was confirmed after $72 \mathrm{~h}$ of STZ injection. Blood samples were collected through the caudal vein and blood glucose levels estimated by diagnostic kits. Rats having blood glucose levels more than or equal to $200 \mathrm{mg} / \mathrm{dL}$ were selected and used for the study.

\section{Biochemical analysis}

At the end of the experiment animals were fasted overnight, anesthetized, and sacrificed to obtain blood samples. Each blood sample was placed in a dry clean centrifuge tube, and centrifuged for $10 \mathrm{~min}$ at $2100 \mathrm{xg}$ to separate the serum. Serum was carefully separated into clean dry Wassermann tubes using a Pasteur pipette and kept at $-80{ }^{\circ} \mathrm{C}$ until analysis.
Serum glucose level $(\mathrm{mg} / \mathrm{dL})$ was determined using a glucose test kit (Egy-Chem, Cairo, Egypt) based on the Trinder et al. glucose oxidase method [37]. Insulin levels were determined by radioimmunoassay according to Clark et al. [38]. Troponin $\mathrm{T}$ levels were determined by means of a third-generation troponin $\mathrm{T}$ assay (Elecsys; Roche Diagnostics, Indianapolis, IN, USA) that uses recombinant cardiac troponin $\mathrm{T}$ as a standard [39]. Triglyceride was determined by the method suggested by Trinder et al. [40]. Total cholesterol was estimated by the method described by Roeschlau et al. [41]. HDL-C and LDL-C were measured using the method described by Assman et al. [42] and VLDL-C was measured using the formula Triglyceride/5 = VLDL-C $(\mathrm{mg} / 100 \mathrm{~mL})$.

\section{Atherogenic index}

The atherogenic index (AI) was determined by the formula suggested by Haglund et al. [43]. Briefly, $\mathrm{AI}=(\mathrm{TC}-\mathrm{HDL}) /$ HDL and coronary heart index (CRI) was calculated as described by Ishiguro et al. using the formula: $\mathrm{CRI}=$ Total cholesterol/HDL-cholesterol [44].

\section{Molecular markers of atherosclerosis and coronary heart disease}

VCAM-1 and ICAM-1 serve as molecular markers of atherosclerosis and predictors of incident coronary heart disease, respectively. ICAM-1 and VCAM-1 levels were determined using Duo Set ELISA kits (R\&D Systems, Minneapolis, MN, USA), in 96-well plates following the manufacturer's protocol. Absorbance was measured at $450 \pm 10 \mathrm{~nm}$ with a Stat Fax 2100 Microplate Reader (MidSci, St. Louis, MO, USA). Levels of VCAM-1 and ICAM-1 were normalized using the total cellular protein concentration, which is proportional to cell number.

\section{Histological examination}

Autopsy samples were taken from the aorta and fixed in $10 \%$ formal saline for $24 \mathrm{~h}$, washed in tap water, then dehydrated in serial dilutions of alcohol (methyl, ethyl, and absolute ethyl). Specimens were cleared in xylene and embedded in paraffin at $56{ }^{\circ} \mathrm{C}$ in a hot air oven for $24 \mathrm{~h}$. Paraffin bees wax tissue blocks were prepared for sectioning at 4 microns $(\mu \mathrm{m})$ thickness by Sledge Microtome (Leica Biosystems Inc., Buffalo Grove, IL, USA). Tissue sections were collected on glass slides, deparaffinized, and stained by hematoxylin and eosin stain for examination by light microscopy [45].

\section{Statistical analysis}

Data analysis was carried out with SPSS Inc. software V22 (IBM, Chicago, IL, USA). One-way analysis of variance was used to determine statistically significant differences between dietary groups $(P<0.05)$. Duncan's test 
was used to compare the significance among groups. All data are presented as \pm standard error of the mean.

\section{Results}

\section{Screening and strain identification}

EPSs from different strains may be different in yield, chemical composition, structure, and physical properties. Forty-two bacterial isolates were isolated from soil samples, with 19 isolates obtained based on the carbohydrate content of their supernatant broth. Although most isolates produced EPS, strain NRC-108 was selected for further study because it demonstrated the highest EPS production (9 g/L). NRC-108 colonies exhibited a creamy mucous on solid medium, and were Gram-positive, rod shaped, and spore forming. The strain produced amylase and arginine and was negative for nitrate reduction, positive for VogesProskauer and indol tests, and acid production. Hence, strain NRC-108 was tentatively identified as Bacillus sp. Comparison of $16 \mathrm{~S}$ rRNA gene sequence among NRC108 and other bacteria from GenBank by BLAST analysis showed the closest strains (99\% similarity) were B. subtilis, B. licheniformis DSM13, and B. pumilus SAFR-032. Phylogenetic analysis results indicated that NRC-108 was most closely related to $B$. subtilis (Fig. 1). The strain is therefore identified as B. subtilus sp. suppress.

\section{Production and isolation of BSEPS}

NRC-108 produced high levels of EPS (10.5 g/L) when fermented at $35{ }^{\circ} \mathrm{C}$ for $96 \mathrm{~h}$, as determined by the phenol-sulfuric acid assay using glucose as a standard. Crude EPS was obtained from fermented broth by ethanol precipitation and dehydration by acetone and diethyl ether. The crude EPS was fractionated on a DEAE-cellulose anion exchange chromatography column (Fig. 2). One major EPS peak was eluted with $0.3 \mathrm{M} \mathrm{NaCl}$, concentrated, dialyzed, and lyophilized to obtain purified BSEPS (white-yellow powder), which was used for subsequent analyses. It produced a positive response to the Bradford test and absorption at $280 / 260 \mathrm{~nm}$, indicating the presence of protein and/or nucleic acid. UV-vis spectroscopy analysis showed that the maximum absorption was $200-220 \mathrm{~nm}$ owing to $n-\sigma^{*}$ and/or $\pi-\pi^{*}$ transitions, characteristic of amine functional groups.

The largest absorbance peak at $210 \mathrm{~nm}$ is characteristic of BSEPS. There was weekly absorption at $280 \mathrm{~nm}$, indicating very small amounts of protein. BSEPS also contained $35.4 \%$ uronic acid as evaluated by $\mathrm{m}$ hydroxydiphenyl colorimetry, $4.9 \%$ sulfate, and $4.1 \% \mathrm{~N}$ acetyl glucose amine. The BSEPS FT-IR spectrum (Fig. 3) displayed a strong band at $3410.49 \mathrm{~cm}^{-1}$, attributed to polysaccharide $\mathrm{O}-\mathrm{H}$ stretching vibration. The $2927.41 \mathrm{~cm}^{-1}$ band was due to $\mathrm{C}-\mathrm{H}$ stretching vibration. A symmetrical stretched peak near $1388.50 \mathrm{~cm}^{-1}$ indicated the presence of carboxyl groups. The prominent absorption at $1633.41 \mathrm{~cm}^{-1}$ was attributed to $\mathrm{C}=\mathrm{O}$ and $\mathrm{C}-\mathrm{N}$ stretching vibrations, whereas absorption at $1132.97 \mathrm{~cm}^{-1}$ was due to the presence of $\mathrm{S}=\mathrm{O}$ and/or $\mathrm{C}-\mathrm{O}-\mathrm{S}$ bonds.

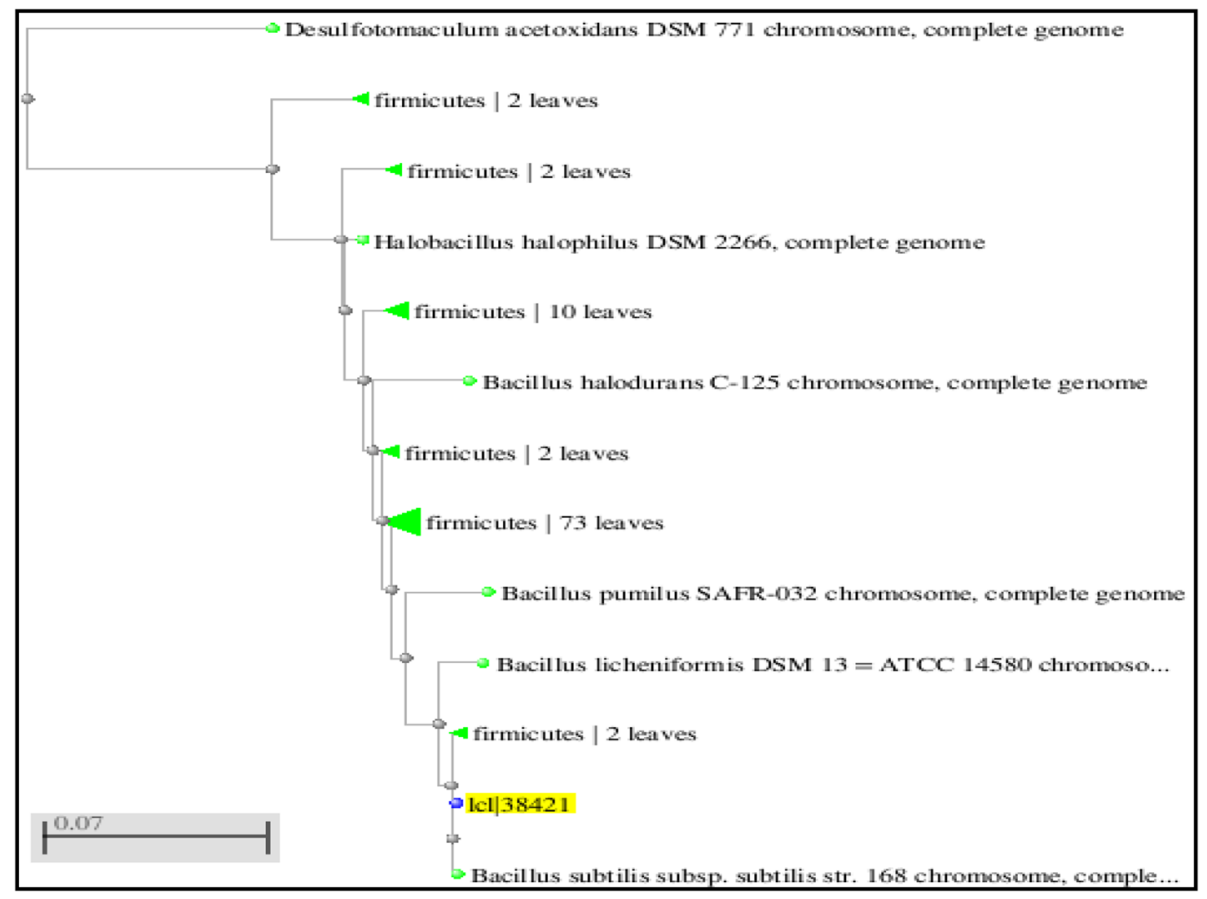

Fig. 1 Phylogenetic neighbor joining tree obtained with the $16 \mathrm{~S}$ rDNA sequences of strain NRC-108 and members of related bacteria 


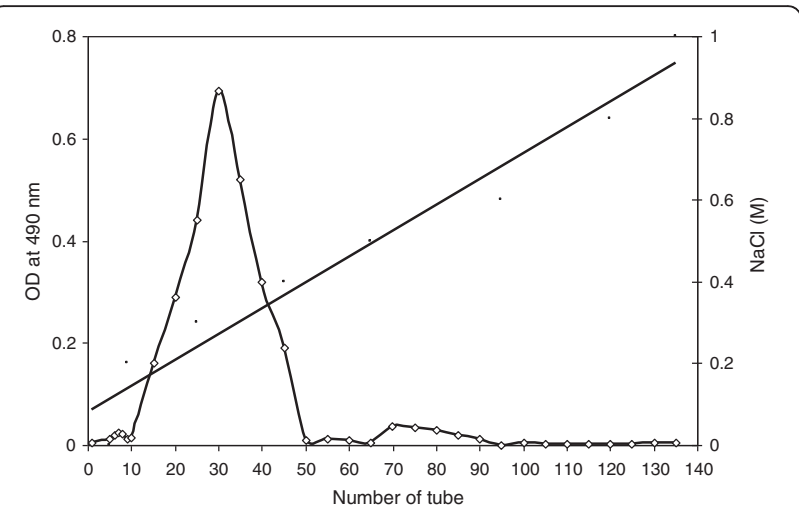

Fig. 2 Elution curve of BSEPS from Bacillus subtilis sp. over DEAEcellulose column. The absorbance at $490 \mathrm{~nm}$ was that of the resulting reactive solutions of exopolysaccharides, phenol and sulfuric acid

Furthermore, characteristic absorptions at $869.74 \mathrm{~cm}^{-1}$ suggest that $\alpha$-configurations were simultaneously present in BSEPS [46].

The BSEPS chemical structure was analyzed by HPLC and compared with monosaccharide standards. BSEPS was composed of mannuronic acid, glucuronic acid, glucose, galactose, and mannose in a molar ratio of 1.6:1.5:1.0:2.3:1.4, respectively (Fig. 4). EPSs from marine bacteria are primarily heteropolysaccharides consisting of pentoses, hexoses, amino sugars, or uronic acids arranged in repeating units. In order to the chemical composition determines position; so, the EPSs contain galactose and mannose that form an unstirred water layer in the gut, which decreases absorption of sugars and lipids. This effect is a property of EPS structure that, by decreasing the rate of gastric emptying, and resisting the convective effects of intestinal contractions, decreases sugar absorption by the small intestine. Thus, to some extent, soluble fibers can be used to prevent the postprandial increase of glucose, making it useful for the treatment of diabetes [47]. EPSs from marine bacteria usually possess hydroxyl and carboxyl groups, which confer a net negative charge and acidic properties. BSEPS molecular weight was calculated for the portions of peaks that lie within the peak ranges. BSEPS $\mathrm{M} w$ was determined to be $1.66 \times 10^{4} \mathrm{~g} \mathrm{~mol}^{-1}$ and the $\mathrm{M} n$ to be $7.64 \times 10^{3} \mathrm{~g} \mathrm{~mol}^{-1}$. The polydispersity index $(\mathrm{Mw} / \mathrm{Mn})$ is a measure of the width of molecularweight distribution 2.17 (Fig. 5).

Most marine EPSs are linear overall and of varying lengths, with a mean molecular mass of $1 \times 10^{5}-3 \times$ $10^{5} \mathrm{Da}$. Organic or inorganic substitutes may also be present [48]. In recent years, there have been reports of deep sea hydrothermal bacteria secreting EPSs; they are typically acidic and contain uronic acid (10-40 \%) and a large molecular weight of up to $1 \times 10^{6} \mathrm{~g} \mathrm{~mol}^{-1}$ [49]. The hypotriglyceridemic effect might be owing to a delayed absorption of triglyceride in the small intestine caused by the high viscosity of the intestinal contents [50]. Therefore, the viscous structure and molecular weight of polysaccharides are thought to be important for limiting absorption in the digestive tract, and increasing cholesterol excretion [50].

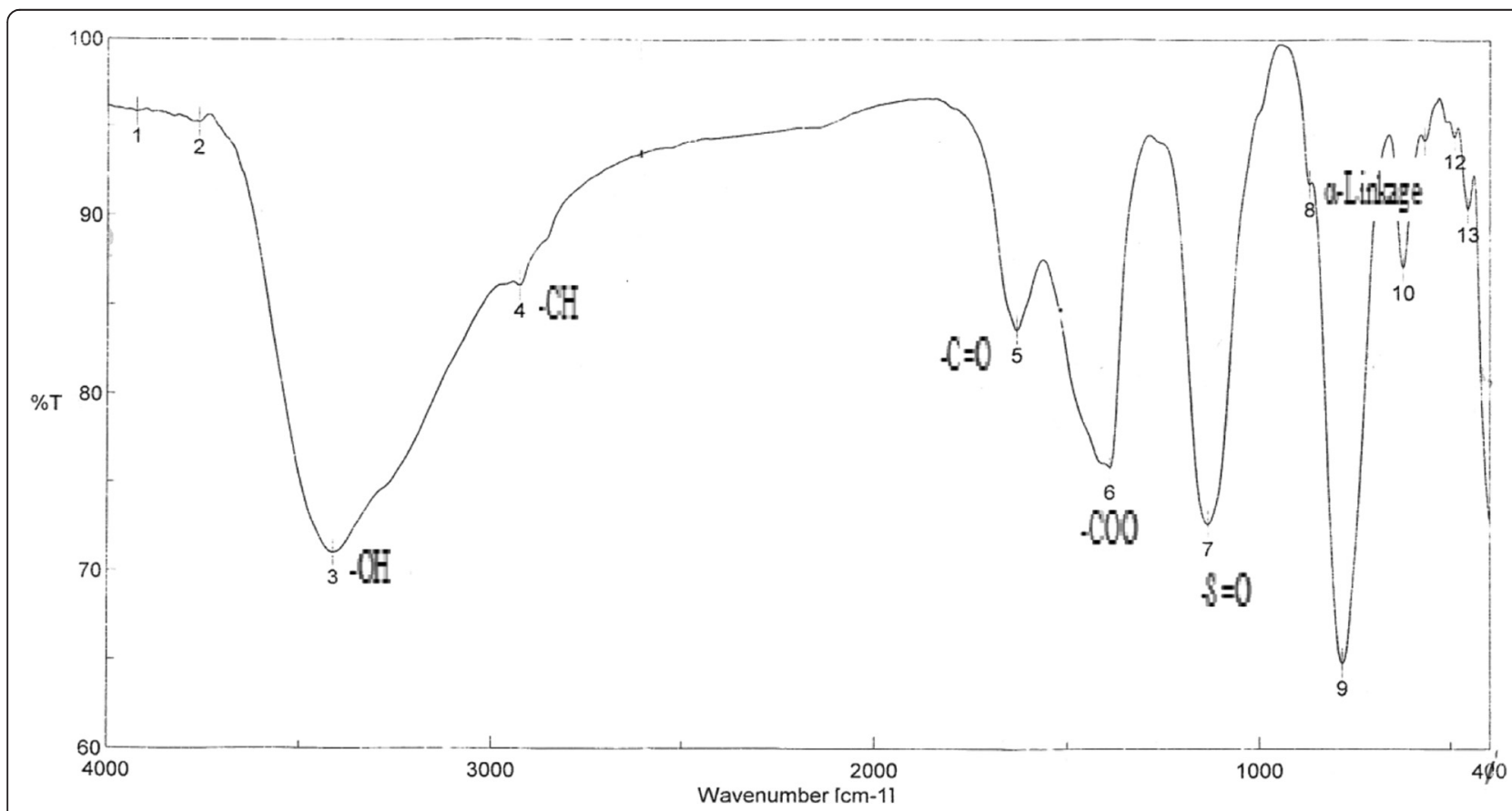

Fig. 3 IR spectrum of the BSEPS from Bacillus subtilis sp. in the range $400-4000 \mathrm{~cm}^{-1}$ 


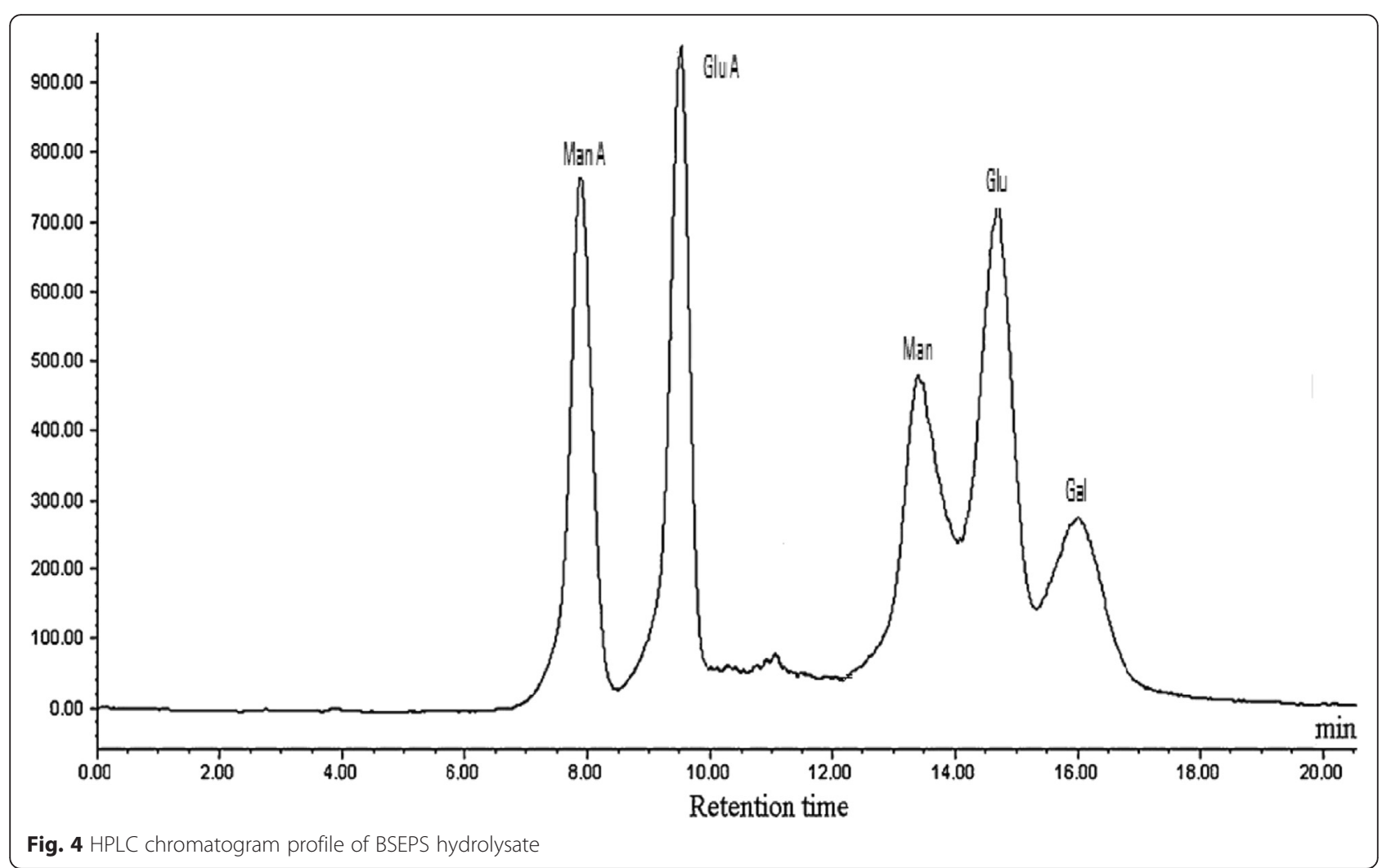

BSEPS scavenging activity of DPPH free radicals

BSEPS was found to significantly inhibit the activity of $\mathrm{DPPH}$ radicals in a dose-dependent manner at concentrations from 30 to $100 \mu \mathrm{g} / \mathrm{mL}[32,33]$. Additional BSEPS $(100 \mu \mathrm{g} / \mathrm{mL})$ lead to increased viscosity and turbidity, prompting us to stop treatment.

Serum glucose and troponin levels increased $(p<0.05)$, and serum insulin levels decreased $(p<0.05)$ in STZ- induced diabetic rats compared with controls (Table 1). EPS supplementation reduced serum glucose and troponin $\mathrm{T}$ levels and increased insulin levels $(p<0.05)$ in the STZ-induced diabetic rats (Group IV).

\section{Serum lipid profile}

The present results noted an increase in serum total cholesterol, triglyceride, LDL-cholesterol, and VLDL-

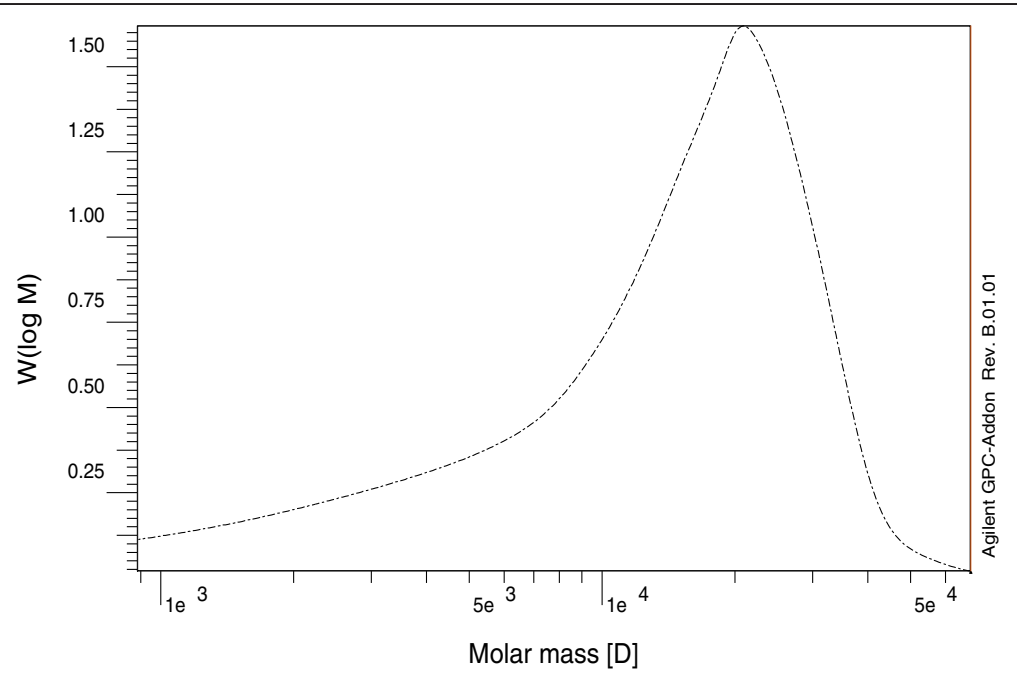

Fig. 5 Weight average molecular weight (Mw) and number average molecular weight (Mn) distributions of BSEPS production by Bacillus subtilis sp 
Table 1 Effect of treatment with polysaccharide on glucose, insulin and troponin concentrations in control, and STZ-induced diabetic rats

\begin{tabular}{lllllll}
\hline Groups & Group I & Group II & Group III & Group IV & $F$ & $P$-value \\
\hline Glucose $(\mathrm{mg} / \mathrm{dl})$ & $78.48 \pm 7.37^{\mathrm{b}}$ & $83.60 \pm 2.99^{\mathrm{b}}$ & $206.50 \pm 6.24^{\mathrm{a}}$ & $82.70 \pm 3.08^{\mathrm{b}}$ & $140^{*}$ & 0.000 \\
Insulin $(\mu \mathrm{IU} / \mathrm{mL})$ & $31.38 \pm 1.24^{\mathrm{a}}$ & $30.47 \pm 2.33^{\mathrm{a}}$ & $11.56 \pm 1.67^{\mathrm{b}}$ & $27.34 \pm 0.99^{\mathrm{a}}$ & $31.87^{*}$ & 0.000 \\
Troponin-T(pg/mL) & $31.43 \pm 3.14^{\mathrm{b}}$ & $33.50 \pm 2.53^{\mathrm{b}}$ & $47.27 \pm 2.18^{\mathrm{a}}$ & $34.65 \pm 2.59^{\mathrm{b}}$ & $7.40^{*}$ & 0.005 \\
\hline
\end{tabular}

Data expressed as mean \pm SE

${ }^{a, b}$ The groups in the same raw with different letters are statistically significant $\left({ }^{*} P<0.05\right)$ using one-way ANOVA followed by Duncan as a post-hoc test

cholesterol levels in STZ-treated rats $(p<0.05)$ and decreased HDL-cholesterol levels compared with normal rats $(p<0.05)$ (Table 2). Interestingly, BSEPS treatment of STZ rats decreased serum lipid profiles (total cholesterol, LDL-cholesterol, VLDL-cholesterol, and triglycerides) $(p<0.05)$ and increased HDL $(p<0.05)$.

\section{Al, CRI, VCAM, and ICAM}

STZ control rats exhibited a profound increase in AI compared with normal rats (Table 3), suggesting that BSEPS treatment decreases AI. Similarly, VCAM and ICAM levels increased in the diabetic group compared with controls, while STZ-induced diabetic rats treated with EPS typically improved, with parameters returning to control levels. Similarly, the data indicate that STZ increases the CRI compared with normal rats $(8.90 \pm 0.56$ vs. $1.6 \pm 0.19)$. In addition, BSEPS-treated rats exhibited an improved CRI $(1.51 \pm 0.09)$, compared with diabetic rats. The acute toxicity data indicate the $\mathrm{LD}_{50}$ was $600 \mathrm{mg} / \mathrm{kg}$, which implies that at this concentration, $50 \%$ of the animals would be killed (Table 4).

\section{Histopathological findings}

We did not observe any major histological differences between groups GI and GII in either the heart tissues or the aorta, by hematoxylin and eosin staining (Fig. 6a-d). In STZ rats beginning on the $4^{\text {th }}$ week, focal hemorrhages, congestion, perivascular edema in the small intramuscular arterioles, and focal muscular hyalinization were consistently observed in the heart (Fig. 6e). The focal area in the degenerated myocardium displayed myo-fibroblast proliferation with a little infiltration of inflammatory cells, as well as congestion in the blood vessels of GIII rats (Fig. 6e). There was also edema in the adventitia, and the aortic tunica intima was irregular. In addition, smooth muscle cells with a perinuclear halo were seen in the tunica media. In contrast, BSEPStreated STZ rats did not show any appreciable change in the heart (Fig. 6f). Normal small intramyocardial arteries were seen in the single-cell layer endothelium. No obvious damages of the aorta were observed in the BSEPStreated group IV (Fig. 6g).

\section{Discussion}

The understanding of cardiac abnormalities that accompany diabetes is of high clinical relevance because, curiously, diabetes increases the risk of coronary -artery disease [51]. Hydroxyl radicals are the most reactive of all the reduced forms of dioxygen and are believed to initiate cell damage both in vitro and in vivo [52]. Gille et al. [53] conclude that STZ-mediated hydroxyl radicals and the generation of reactive oxygen species may be crucial effectors in $\beta$-cell damage. Our data show a significant decrease in the concentration of DPPH radicals owing to the scavenging ability of BSEPS.

Our study investigated the effect of EPS treatment on the lipid profile and cardiovascular disease risk predictor (AI and CRI) in STZ-induced diabetic rats. Generally, increase blood glucose levels characterize STZ-induced diabetes, consistent with our results. Previously, STZ diabetic animals were shown to exhibit tissue injury and diabetic complications that involve the cardiovascular, gastrointestinal, and nervous systems as well as the vas deferens, kidney, eyes, and urinary bladder through increased lipid peroxidation and oxidative stress [54]. Our results indicate that diabetes induced a significant elevation of troponin levels. Diabetes triggers ongoing myocardial damage, which manifests as elevated serum

Table 2 Effect of treatment with polysaccharide on lipid profile in control, and STZ-induced diabetic rats

\begin{tabular}{|c|c|c|c|c|c|c|}
\hline Groups & Group I & Group II & Group III & Group IV & $\mathrm{F}$ & $P$-value \\
\hline Total cholesterol (mg/dl) & $43.70 \pm 1.53^{b}$ & $44.52 \pm 1.46^{b}$ & $101.93 \pm 7.38^{\mathrm{a}}$ & $48.20 \pm 2.46^{b}$ & $45.86^{*}$ & 0.000 \\
\hline Triglycerides (mg/dl) & $40.75 \pm 1.72^{b}$ & $45.43 \pm 1.59^{\mathrm{b}}$ & $130.82 \pm 3.23^{\mathrm{a}}$ & $47.22 \pm 2.73^{b}$ & $309.01^{*}$ & 0.000 \\
\hline LDL-C (mg/dl) & $11.48 \pm 3.29^{b}$ & $8.80 \pm 3.24^{b}$ & $64.33 \pm 7.26^{\mathrm{a}}$ & $7.27 \pm 1.91^{b}$ & $38.54^{*}$ & 0.000 \\
\hline $\mathrm{HDL}-\mathrm{C}(\mathrm{mg} / \mathrm{dl})$ & $28.10 \pm 1.92^{\mathrm{a}}$ & $27.58 \pm 2.47^{a}$ & $11.43 \pm 0.51^{b}$ & $32.21 \pm 1.46^{\mathrm{a}}$ & $29.29^{*}$ & 0.000 \\
\hline VLDL-C (mg/dl) & $8.15 \pm 0.34^{b}$ & $9.09 \pm 0.32^{b}$ & $26.16 \pm 0.65^{a}$ & $9.44 \pm 0.55^{b}$ & $309.01^{*}$ & 0.000 \\
\hline
\end{tabular}

Data expressed as mean \pm SE

${ }^{a, b}$ The groups in the same raw with different letters are statistically significant $\left({ }^{*} P<0.05\right)$ using one-way ANOVA followed by Duncan as a post-hoc test 
Table 3 Effect of treatment with polysaccharide on serum concentration of ICAM and VCAM in control, and STZ-induced diabetic rats

\begin{tabular}{lllllll}
\hline Groups & Group I & Group II & Group III & Group IV & F & $P$-value \\
\hline Al $(\mathrm{mg} / \mathrm{dl})$ & $0.59 \pm 0.17^{\mathrm{b}}$ & $0.68 \pm 0.2^{\mathrm{b}}$ & $7.73 \pm 0.59^{\mathrm{a}}$ & $0.51 \pm 0.08^{\mathrm{b}}$ & $112.97^{*}$ & 0.000 \\
CRI $(\mathrm{mg} / \mathrm{dl})$ & $1.60 \pm 0.19^{\mathrm{b}}$ & $1.58 \pm 0.20^{\mathrm{b}}$ & $8.90 \pm 0.56^{\mathrm{a}}$ & $1.51 \pm 0.09^{\mathrm{b}}$ & $128.204^{*}$ & 0.000 \\
ICAM $(\mathrm{ng} / \mathrm{ml})$ & $6.03 \pm 0.12^{\mathrm{c}}$ & $5.21 \pm 0.13^{\mathrm{d}}$ & $7.96 \pm 0.25^{\mathrm{a}}$ & $6.89 \pm 0.17^{\mathrm{b}}$ & $42.00^{*}$ & 0.000 \\
VCAM $(\mathrm{ng} / \mathrm{ml})$ & $16.82 \pm 1.34^{\mathrm{b}}$ & $17.35 \pm 0.69^{\mathrm{b}}$ & $23.98 \pm 0.45^{\mathrm{a}}$ & $18.34 \pm 0.99^{\mathrm{b}}$ & $27.90^{*}$ & 0.000 \\
\hline
\end{tabular}

Data expressed as mean \pm SE

Data expressed as mean $\pm \mathrm{SE}$
$\mathrm{a}, \mathrm{b}, \mathrm{d}, \mathrm{d}$
The groups in the same raw with different letters are statistically significant $\left({ }^{*} P<0.05\right)$ using one-way ANOVA followed by Duncan as a post-hoc test

cardiac troponin $\mathrm{T}$, increasing the risk for further cardiac events in patients with chronic heart failure $[55,56]$.

Our data indicate that BSEPS accentuates hyperlipidemia as efficiently as other polysaccharides [56]. BSEPS protects against increases in glucose and decreases in insulin that might be attributed to its ability to reduce hyperglycemia. This might be via the inhibition of hepatic gluconeogenesis and glucose production from the liver, which is accompanied by suppression of lipolysis in adipose [57]. The abnormal high level of serum lipids in diabetes is mainly due to an increase in the mobilization of free fatty acids from peripheral fat depots by lipolysis [58]. Increased release of free fatty acids increases the production of ketone bodies and triglyceride synthesis. In the present investigation, triglycerides were increased significantly in diabetic control rats. Insulin deficiency depletes the activity level of lipoprotein lipase, thus leading to abnormal lipoprotein metabolism in diabetes and resulting in hypertriglyceridemia [59].

A major reason for cardiovascular disease in diabetes is the lipid abnormalities that accompany atherosclerosis. Therefore, an ideal treatment for diabetes, in addition to glycemic control, ought to facilitate production of healthy lipid profiles [60]. The present results elucidated a significant increase in serum total lipids, total cholesterol, triglyceride, LDL-cholesterol, and VLDL-cholesterol levels in STZ control rats and decreased HDL-cholesterol levels compared with normal rats. These results are consistent with those of other investigators [61]. Additionally, increased levels of serum triglycerides could also contribute

\begin{tabular}{|c|c|}
\hline Doses $(\mathrm{mg} / \mathrm{kg})$ & Result of first phase (mortality) $n=3$ in each group \\
\hline 10 & $0 / 3$ \\
\hline 100 & $0 / 3$ \\
\hline 1000 & $1 / 3$ \\
\hline Doses $(\mathrm{mg} / \mathrm{kg})$ & Result of $2^{\text {nd }}$ phase (mortality) $n=3$ \\
\hline 1600 & $1 / 3$ \\
\hline 2900 & $2 / 3$ \\
\hline 5000 & $2 / 3$ \\
\hline
\end{tabular}

The $L D 50$ value of BSEPS $=600 \mathrm{mg} / \mathrm{kg}$ to reduced clearance of triglycerides, secondary to decreased activity of lipoprotein lipase [62]. The high level of LDL-cholesterol found in STZ rats may be attributed to cholesterol-mediated down-regulation of LDL receptors [63]. Reduction in HDL following STZ may be because of the acceleration of apoA-I clearance from the plasma owing to elevated cholesterol [63]. Moreover, diabetes often presents with impaired carbohydrate metabolism, and increased lipolysis causes accumulation of acetyl CoA. Increased availability of acetyl CoA leads to synthesis of cholesterol and causes hyperlipidemia [64]. Notably, increased total cholesterol levels were restored in BSEPStreated diabetic rats. Insulin deficiency is associated with hypercholesterolemia owing to metabolic abnormalities [65]. For example, serum lipids are increased by lipolysis as a result of insulin deficiency in diabetic rats [66]. Usually, insulin increases lipogenesis and decreases lipolysis and ketogenesis. However, in the diabetic condition, insulin deficiency reverses the above-mentioned role in lipid metabolism. Triglycerides are neutral fats and a major energy reserve for the body stored as adipose tissue. In the present investigation, triglycerides increased significantly following STZ treatment. Diabetes increases lipolysis and produces more free fatty acids. Increased free fatty acids increases production of ketone bodies and triglyceride synthesis. The increased level of triglycerides was maintained in diabetic rats following BSEPS treatment.

LDL plays a significant role in atherosclerosis and related diseases. In the present study, LDL levels increased in STZ-induced diabetic rats. Importantly, LDL transports cholesterol from the liver to peripheral tissues, and is formed from VLDL-cholesterol. VLDL levels also increased in the present study after STZ injection, denoting increased production of LDL-cholesterol. The effective control of glycemic imbalance will reduce the VLDL and triglyceride levels [67]. HDL cholesterol plays a role in preventing atherosclerosis by transporting cholesterol from peripheral tissues to the liver for excretion. A decrease in HDL was observed in the present study, which increases the chances of atherosclerosis. Restoration of the HDL decrease in treated diabetic rats shows the potential alleviating capacity of BSEPS. Increased serum total cholesterol and LDL levels are negatively correlated with HDL levels [67]. An increase in HDL-cholesterol is associated 

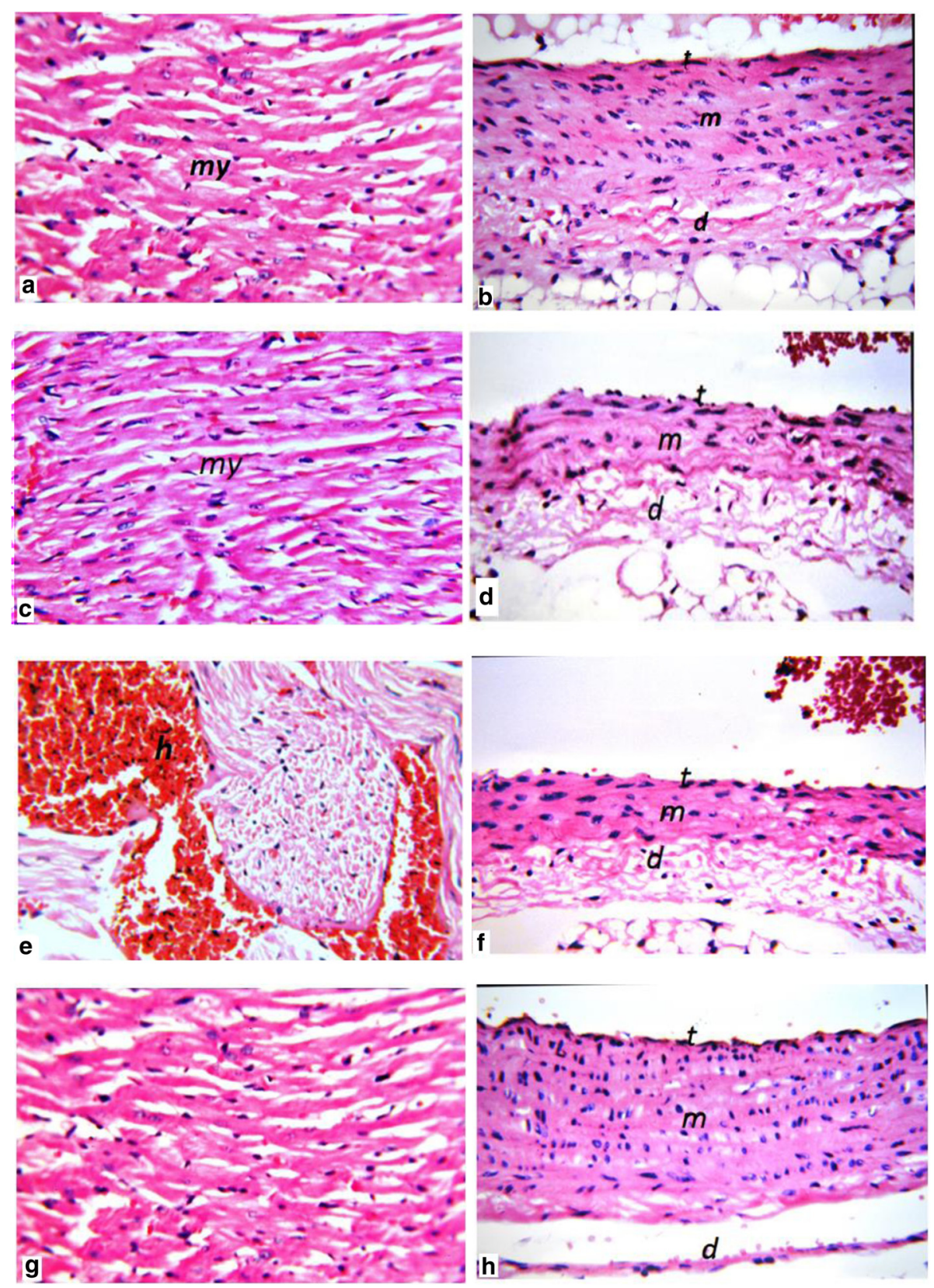

Fig. 6 Heart: (a). Group I There was no histopathological alteration and the normal histological structure of the myocardium H\&EX64. Aorta: (b) Group I There was no histopathological alteration and the normal histological structure of the tunica intima, media and adventitia $\mathrm{H} \& \mathrm{E} \times 64$. $\mathbf{c}$ Group II There was no histopathological alteration as recorded in heart tissue H\& Ex64. Aorta (d): Group II There was no histopathological alteration as recorded H\& E×64. e: Group III, Focal haemorrhages were detected in the myocardium H\& E×64. Aorta (f): There was oedema in the adventitia (group III) H\& E×64. g; Group IV, there was no histopathological alteration the normal histological structure of the myocardium H\& Ex64. Aorta (h): Group IV there was no histopathological alteration as recorded H\& Ex 64

with a decrease in coronary risk, which is associated with elevated levels of total cholesterol, especially LDLcholesterol [68]. The antihyperglycemic effect of BSEPS and hence an improved diabetic state may lead to a reduction in VLDL levels, and consequently LDL levels.

The AI and CRI are also quite high in STZ-induced diabetic rats. Elevated serum lipids often indicate coronary heart disease. BSEPS treatment improved the worst condition to its normal level as compared with the STZ group, as shown through increased HDLcholesterol. Importantly, HDLs protect against or reverse atherosclerosis by their ability to serve as acceptor particles for macrophage cholesterol efflux, prevention of endothelial dysfunction, and maintenance of endothelial 
integrity [69]. Moreover, the increase in HDL cholesterol is associated with a decrease in coronary risk [70].

The histological findings showed that cardiac structural organization was disturbed in STZ-induced diabetic rats. Inflammatory histological change in cardiac tissue indicates myocardial injury. Previous studies reported diabetic cardiomyopathy as characterized by systolic or diastolic dysfunction and cardiac fibrosis in diabetes patients [71]. In a state of insulin deficiency (type 1 diabetes), there is a decrease in protein synthesis, an increase in protein degradation, and defective mitochondrial function with loss of myofibrils in the heart muscle [72, 73], which may disrupt the cardiac myo-fibers. Aortic wall histology of diabetic rats indicated an increase in thickness. In summary, our findings suggest BSEPS extract provides a protective role for atherosclerosis in STZ-induced diabetic rats.

\section{Conclusion}

It is concluded that the BSEPS from Bacillus subtilus sp. Suppress is effective in the management of the hyperglycemias as well as dyslipidemia in induced conditions like diabetes. Treatment with BSEPS maintained the histological integrity of the cardiac tissues by reducing the degenerative changes in the myocardium as well as in the aortic tissues by decreasing the thickness of tunica media. Also free radical scavenging activity also increased with increasing concentration in the range of $30-100 \mu \mathrm{g} / \mathrm{mL}$. These in-vitro assays of antioxidant indicate that this BSEPS is a significant source of natural antioxidant, which might be helpful in preventing the progress of various oxidative stresses.

\section{Abbreviations}

Al: atherogenic index; CAM: complementary and alternative medicine; CDV: cardiovascular disease; CHD: coronary heart disease; DM: diabetes mellitus; DPPH: diphenyl-2-picryl-hydrazyl; EPS: exopolysaccharides; FTIR: fourier-transform infrared; GPC: gel-permeation chromatography; HCl: hydrochloric acid; HDL: high density lipoprotein; HPLC: high performance liquid chromatography; ICAM: intercellular adhesion molecule-1; KBr: potassium bromide; LDL: low-density lipoprotein; PCR: polymerase chain reaction; RID: refractive index detector; rRNA: ribosomal ribonucleic acid; STZ: streptozotocin; UV: ultraviolet; VCAM: vascular cell adhesion molecule-1; VLDL: very low density lipoprotein; WHO: World Health Organization.
}

\section{Competing interests}

The authors declare that they have no competing interests.

\begin{abstract}
Authors' contributions
AlH and MAGh did the experimental work of biology part, while MGM and MSA did the experimental microbiology and chemistry work of part. MGM and MSA contributed to the study design. All authors took part in planning the study design, supervising the study design, contributed to the analysis and writing of the manuscript, edited the paper, revising it critically for important intellectual content and provided the final version. All authors contributed to and have approved the final manuscript.
\end{abstract}

\section{Acknowledgments}

The authors are grateful to Dr. Adel M. Bakeer Kholoussy, Department of Pathology, Faculty of Veterinary Medicine, Cairo University for his help in the examination of the histopathological slides and for his valuable comments.

\section{Funding statement}

No fund.

\section{Author details}

${ }^{1}$ Department of Radioisotopes, Nuclear Research Centre, Atomic Energy Authority, Dokki, Giza, Egypt. ${ }^{2}$ Microbial Biotechnology Department, National Research Centre, 33 Bohouth St., Dokki, Giza 12311, Egypt.

Received: 27 May 2015 Accepted: 23 March 2016

Published online: 31 March 2016

\section{References}

1. Eiselein L, Schwartz HJ, Rutledge JC. The challenge of type 1 diabetes mellitus. ILAR J. 2004;45:231-6.

2. Shaw J, Sicree R, Zimmet P. Global estimates of the prevalence of diabetes for 2010 and 2030. Diabetes Res Clin Pract. 2010;87:4-14.

3. Roglic G, Unwin N. Mortality attributable to diabetes: estimates for the year 2010. Diabetes Res Clin Pract. 2010:87:15-9.

4. Qiong L, Yizhong C, Jun Y, Mei S, Harold C. Hypoglycemic and hypolipidemic effects and antioxidant activity of fruit extracts from Lycium barbarum. Life Sci. 2004;76:137-49.

5. Erejuwa O. Effect of honey in diabetes mellitus: matters arising. J Diabetes Metab Disord. 2014;13:23.

6. Zhang YB, Zhao Y, Cui HF, Cao CY, Guo JY, Liu S. Comparison of hypoglycemic activity of fermented mushroom of Inonotus obliquus rich in vanadium and wild-growing I. obliquus. Biol Trace Elem Res. 2011;144:1351-7.

7. Matough FA, Budin SB, Hamid ZA, Alwahaibi N, Mohamed J. The Role of Oxidative Stress and Antioxidants in Diabetic Complications. Sultan Qaboos Univ Med J. 2012;12(1):5-18.

8. Stiles MC, Seaquist ER. Cerebral structural and functional changes in type 1 diabetes. Minerva Med. 2010;101:105-14.

9. Donot F, Fontana A, Baccou JC, Schorr-Galindo S. Microbial exopolysaccharides: main examples of synthesis, excretion, genetics and extraction. Carbohydr Polym. 2012;87:951-62.

10. Kim KJ, Lee $\mathrm{OH}$, Han CK, Kim YC, Hong HD. Acidic polysaccharide extracts from Gastrodia Rhizomes Suppress the atherosclerosis risk index through inhibition of the serum cholesterol composition in Sprague Dawley rats fed a high-fat diet. Int J Mol Sci. 2012;13(2):1620-31.

11. Cabral De Melo FCB, Barsato D, Buzato JB, Celligoi MAPC. Levan from Bacillus subtilis natto: optimization of prod activity using factorial design. J Biotechnol. 2010;150S:S378.

12. Gummadi SN, Kumar K. Production of extracellular water insoluble $\beta-1,3-$ glucan (curdlan) from Bacillus sp. SNC07. Biotechnol Bioprocess Eng. 2005: 10(6):546-51.

13. Larpin S, Sauvageot N, Pichereau V, Laplace J, Auffray Y. Biosynthesis of exopolysaccharide by a Bacillus licheniformis strain isolated from ropy cider. Int J Food Microbiol. 2002;77:1-9.

14. Corsaro MM, Grant WD, Grant S, Marciano CE, Parrilli M. Structure determination of an exopolysaccharides from an alkaliphilic bacterium closely related to Bacillus spp. Eur J Biochem. 1999;264:554-61.

15. Kodali VP, Das S, Sen R. An EPS from a probiotic: biosynthesis dynamics, composition and emulsifying activity. Food Res Int. 2009;42:695-9.

16. Zheng H, Shen XQ, Bu GH, Luo YK. Effects of pH, temperature and enzymeto-substrate ratio on the antigenicity of whey protein hydrolysates prepared by alcalase. Int Dairy J. 2008;18:1028-33.

17. Kim YO, Kim HK, Bae KS, Yu JH, Oh TK. Purification and properties of a thermostable phytase from Bacillus sp. DS11. Enzyme Microb Technol. 1998; 22:2-7.

18. Dubois M, Gilles KA, Hamilton JK, Rebers PA, Smith F. Colorimetric method for determination of sugars and related substances. Anal Chem. 1965;28: 350-6.

19. Cappuccino JG, Sherman N. Microbiology laboratory manual. New Delhi: Pearson Education Inc.; 2004

20. Weisburg WG, Barns SM, Pelletier DA, Lane DJ. 16 S ribosomal DNA amplification for phylogenetic study. J Bacteriol. 1991;173:697-703.

21. Tamura K, Dudley J, Nei M, Kumar S. Molecular Evolutionary Genetics Analysis (MEGA) software version 4.0. Mol Biol Evol. 2007;24:1596-9.

22. Jiang ZD, Jensen PR, Fenical W. Lobophorins A and B, new antiinflammatory macrolides produced by a tropical marine bacterium. Bioorg Med Chem Lett. 2003;9(14):2003-6. 
23. Read RR, Costerton JW. Purification and characterization of adhesive exopolysaccharides from Pseudomonas putida and Pseudomonas fluorescens. Can J Microbiol. 1987;33:1080-90.

24. Asker MMS, Ahmed YM, Ramadan MF. Chemical characteristics and antioxidant activity of exopolysaccharides fractions from Microbacterium terre genes. Carbohydr Polym. 2009;77:563-7.

25. Sudhamani SR, Tharanathan RN, Prasad MS. Isolation and characterization of an extracellular polysaccharide from Pseudomonas caryophylli CFR 1705. Carbohydr Polym. 2004;56:423-7

26. Filisetti-Cozzi TMC, Carpita C. Measurement of uronic acids without interference from neutral sugars. Anal Biochem. 1991;197:157-62.

27. Dodgson KS, Price RG. A note on the determination of the ester sulfate content of sulfated polysaccharides. Biochem J. 1962;84:106-10.

28. Morgan WT, Elson LA. A colorimetric method for the determination of $\mathrm{N}$ acetylglucosamine and N-acetylchrondrosamine. Biochem J. 1934;28(3):988-95.

29. El-Sayed OH, Ismail SA, Ahmed YM, Abd El-Samei M, Asker MMS. Studies on the production of sulfated polysaccharide by locally isolated bacteria. Egypt Pharm J. 2007:4:439-52.

30. Ray B. Polysaccharides from Enteromorpha campressa: isolation, purification and structural features. Carbohydr Polym. 2006;66:408-16.

31. Jun HI, Lee $H$, Song GS, Kim YS. Characterization of the pectic polysaccharide from Pumpkin Peel LWT. Food Sci Technol. 2006;39:554-6.

32. You L, Gao Q, Feng M, Yang B, Ren J, Gu L, Cui C, Zhao M. Structural characterization of polysaccharides from Tricholoma matsutake and their antioxidant and antitumour activities. Food Chem. 2013;138:2242-9.

33. Asker MMS, Shawky BT. Structural characterization and antioxidant activity of an extracellular polysaccharide isolated from Brevibacterium otitidis BTS 44. Food Chem. 2010;123:315-20.

34. Usta MF, Bivalacqua TJ, Yang DY, Ramanitharan A, Sell DR, Viswanathan A, et al. The protective effect of amino guanidine on erectile function in streptozotocin diabetic rats. J Urol. 2003;170:1437-42.

35. Sharma AK, Sharma A, Kumari R, Kishore K, Sharma D, Srinivasan PB, et al. Sitagliptin, sitagliptin and metformin, or sitagliptin and amitriptyline attenuate streptozotocin-nicotinamide induced diabetic neuropathy in rats. J Biomed Res. 2012;26:200-10.

36. Lorke D. A new approach to tropical acute toxicity testing. Arch Toxicol. 1983;53:275-87.

37. Trinder P. Determination of blood glucose using an oxidase-peroxidase system with a non-carcinogenic chromogen. J Clin Pathol. 1969;22:158-61.

38. Clark PM. Assays for insulin, proinsulin (s), and C-peptide. Ann Clin Biochem. 1999;36:541-64

39. Hallermayer K, Klenner D, Vogel R. Use of recombinant human cardiac troponin $\mathrm{T}$ for standardization of third generation troponin $\mathrm{T}$ methods. Scand J Clin Lab Invest. 1999;230:128-31.

40. Trinder P. Determination of serum cholesterol by enzymatic colorimetric method. Ann Clin Biochem. 1969;6:24-7.

41. Roechlau P, Bernt E, Gruber W. Kinetics of the cholesterol, sulfuric acid reaction. A fast kinetic method for serum cholesterol. Clin Chem Clin Biochem. 1974;12:403-8.

42. Assmann G. Cholesterol determination in high density lipoproteins separated by three different methods. Internist. 1979;20:595-604.

43. Haglund O, Luostarinen R, Wallin R, Wibell L, Saldeen T. The effect of fish oil triglycerides, cholesterol, fibrinogen and malondialdehyde in humans supplemented with vitamin E. J Nutr. 1991;121:165-9.

44. Ishiguro $\mathrm{H}$, Arinami $\mathrm{T}$, Akazawa $\mathrm{S}$, Enomoto $\mathrm{M}$, Mitushio $\mathrm{H}$, Fujishiro $\mathrm{H}$, et al. Association study between the $-141 \mathrm{C}$ Ins polymorphisms of the dopamine D2 receptor gene and alcoholism. Alcohol Clin Exp Res. 1998;22:845-8.

45. Bancroft JD, Stevens A. Theory and practice of histological techniques. 4th ed. New York: Churchill Livingstone; 1996.

46. Asker M, EL Sayed OH, Mahmoud MG, Ramadan MF. Chemical structure and antioxidant activity of a new exopolysaccharides produced from Micrococcus luteus. J Genet Eng Biotechnol. 2014;12(2):121-6.

47. De Paula ACCFF, Sousa RV, Figueiredo-Ribeiro RCL. Hypoglycemic activity of polysaccharide fractions containing bglucans from extracts of Rhynchelytrum repens (Willd.) C.E. Hubb., Poaceae. Braz J Med Biol Res. 2005;38:885-93.

48. Nichols MC, Bowman JP, Guezennec J. Effects of incubation temperature on growth and production of exopolysaccharides by an antarctic sea ice bacterium grown in batch culture. Appl Environ Microbiol. 2005;71(7):3519-23.

49. Guezennec J. Deep-sea hydrothermal vents: a new source of innovative bacterial exopolysaccharides of biotechnological interest? J Ind Microbiol Biotechnol. 2002;29:204-8.
50. Yukiko Y, Sogawa I, Nishina A. Improved hypolipidemic effects of xanthan gum-galactomannan mixtures in rats. Biosci Biotechnol Biochem. 2000;64: 2165-7.

51. $Y u Z B$, Wei H, Jin JP. Chronic coexistence of two troponin T isoforms in adult transgenic mouse cardiomyocytes decreased contractile kinetics and caused dilatative remodeling. Am J Physiol Cell Physiol. 2012;303:C24-32.

52. Rollet-Labelle E, Grange MJ, Elbim C, Marquetty C, Gougerot-Pocidalo MA, Pasquier C. Hydroxyl radical as a potential intracellular mediator of polymorphonuclear neutrophil apoptosis. Free Radic Biol Med. 1998;24(4): 563-72.

53. Gille L, Schott-Ohly P, Friesen N, Schulte im Walde S, Udilova N, Nowl H, Gleichmann H. Generation of hydroxyl radicals mediated by streptozotocin in pancreatic islets of mice in vitro. Pharmacol Toxicol. 2002;90(6):317-26.

54. Lemhadri A, Hajji L, Michel JB, Eddouks M. Cholesterol and triglycerides lowering activities of caraway fruits in normal and streptozotocin diabetic rats. J Ethnopharmacol. 2006;106:321-6.

55. Setsuta K, Kitahara Y, Arae M, Ohbayashi T, Seino Y, Mizuno K. Elevated cardiac troponin T predicts adverse outcomes in hypertensive patients. Int Heart J. 2011;52(3):164-9.

56. Soeda $\mathrm{S}$, Ohmagari $\mathrm{H}$, Shimeno $\mathrm{H}$, Nagamatsu A. Preparation of aminated fucoidan and its evaluation as an antithrombotic and antilipemic agent. Biol Pharm Bull. 1994;17:784-8.

57. Postic C, Dentin R, Girard J. Role of the liver in the control of carbohydrate and lipid homeostasis. Atherosclerosis. 2001;158:12.

58. Bopanna KN, Kannan J, Sushma G, Balaraman R, Rathod SP. Antidiabetic and antihyperlipidemic effect of neem seed, kernal powder on alloxan diabetic rabbits. Indian J Pharm. 1997;9:162-7.

59. Ranganathan G, Li C, Kern PA. The translational regulation of lipoprotein lipase. J Biol Chem. 2001;272:2519-25.

60. Rajasekaran S, Jaykar B, Anandan R, Aboobacker KP, Vannamalar S. Antidiabetic activity of leaves of Zizyphus nummularia by dexamethasone induced diabetic rat model. Int J PharmTech Res. 2013;5(2):844-51.

61. Hassan S, Abd El-Twab S, Hetta M, Mahmoud B. Improvement of lipid profile and antioxidant of hypercholesterolemic albino rats by polysaccharides extracted from the green alga Ulva lactuca Linnaeus. Saudi J Biol Sci. 2011;18(4):333-40.

62. Nofer JR, Kehrel B, Fobker M, Levkau B, Assmann G, von Eckardstein A. HDL and arteriosclerosis: beyond reverse cholesterol transport. Atherosclerosis. 2002;161(1):1-16.

63. Mustad VA, Etherton TD, Cooper AD, Mastro AM, Pearson TA, Jonnalagadda SS, et al. Reducing saturated fat intake is associated with increased levels of LDL receptors on mononuclear cells in healthy men and women. J Lipid Res. 1997;38(3):459-68.

64. Tabit CE, Chung WB, Hamburg NM, Vita JA. Endothelial dysfunction in diabetes mellitus: molecular mechanisms and clinical implications. Rev Endocr Metab Disord. 2010;11:61-74.

65. Satyanarayana U, Hakrapani CU. Biochemistry. 3rd ed. Kolkatta: Books and Allied (P) Ltd; 2007.

66. Shirwaikar A, Rajendran K, Kumar CD, Bodla R. Antidiabetic activity of aqueous leaf extracts of Annona squamosa in streptozotocin-nicotinamide type 2 diabetic rats. J Ethnopharmacol. 2004;91:171-5.

67. Stephen NJ. Relationship between LDL, HDL, blood pressure and atheroma progression in the coronaries. Curr Opin Lipidol. 2004;20:491-6.

68. Temme EH, Van HPG, Schouten EG, Kesteloot H. Effect of a plant sterolenriched spread on serum lipids and lipoprotein in mildly hypercholesterolaemic subjects. Acta Cardiol. 2002;57:111-5.

69. Linsel-Nitschke $P$, Tall AR. HDL as a target in the treatment of atherosclerotic cardiovascular disease. Nat Rev Drug Discov. 2005;4(3):193-205.

70. Singh SK, Kesari AN, Gupta RK, Jaiswal D, Watal G. Assessment of antidiabetic potential of Cynodon dactylon extract in streptozotocin diabetic rats. J Ethnopharmacol. 2007;114:174-9.

71. Hayat SA, Patel B, Khattar RS, Malik RA. Diabetic cardiomyopathy: mechanisms, diagnosis and treatment. Clin Sci. 2004;107:539-57.

72. Thent ZC, Lin TS, Das S, Zakaria Z. Histological changes in the heart and the proximal aorta in experimental diabetic rats fed with piper sarmentsoum. Afr J Tradit Complement Altern Med. 2012;9(3):396-404.

73. Malone Jl, Schocken DD, Morrison AD, Gilbert-Barness E. Diabetic cardiomyopathy and carnitine deficiency. J Diabetes Complicat. 1999;13(2): 86-90. 